\title{
Aeromagnetic Mapping of Singo Granite in Kiboga Area of Central Uganda
}

\author{
Durojaye $0.0^{1}$ and Oluwadebi A.G ${ }^{2}$ \\ University of Twente, Faculty of Geo-information Sciences, ITC, Netherlands ${ }^{1}$ \\ School of Earth, Atmospheric and Environmental Sciences, University of Manchester, M13 9PL, UK ${ }^{2}$
}

\begin{abstract}
Mapping of Singo granite in Kiboga area of Central Uganda was carried out with the use Aeromagnetic remote sensing data. The depth, source, subsurface and surface structures of the magnetic anomaly in Singo granite were investigated with the aeromagnetic dataset. Different types of filtering were performed on OASIS Montaj Software to enhance interpretation of the aeromagnetic data; these include Vertical Derivatives, Analytical Signal, and Total Magnetic Intensity. Vertical derivatives and analytical signal reveals the structural features within and around the Singo granite while total magnetic intensity shows the frequency of the magnetic source. 3D Euler deconvolution was used to determine the depth of the magnetic anomaly within Singo granite.
\end{abstract}

Keywords: Singo granite, Aeromagnetic, Vertical Derivatives, Analytical Signal, Total Magnetic Intensity, 3D Euler deconvolution.

\section{INTRODUCTION}

This study focuses on mapping of Singo granite in Kiboga which therefore makes magnetic surveys data significant area of Central Uganda using aeromagnetic remote sensing in generating 3D geological information [1]. Magnetic data. The depth, source, subsurface and surface structures data involve measuring the variations in the earth's of magnetic anomaly around Singo granite were magnetic field caused by the distribution of magnetic investigated using aeromagnetic remote sensing datasets. minerals in the rocks that make up the upper part of the Various studies have shown significant results in the use earth's crust.

of integrated remote sensing and geophysical data to map surface and subsurface geology [1-4]. Other airborne geophysical mapping tools like gamma ray spectrometry only provide information about the surface whereas magnetic data show information about the subsurface,

\section{LOCATION AND GEOLOGY OF STUDY AREA}

The study area is situated in Kiboga area of central Uganda (Figure 1).

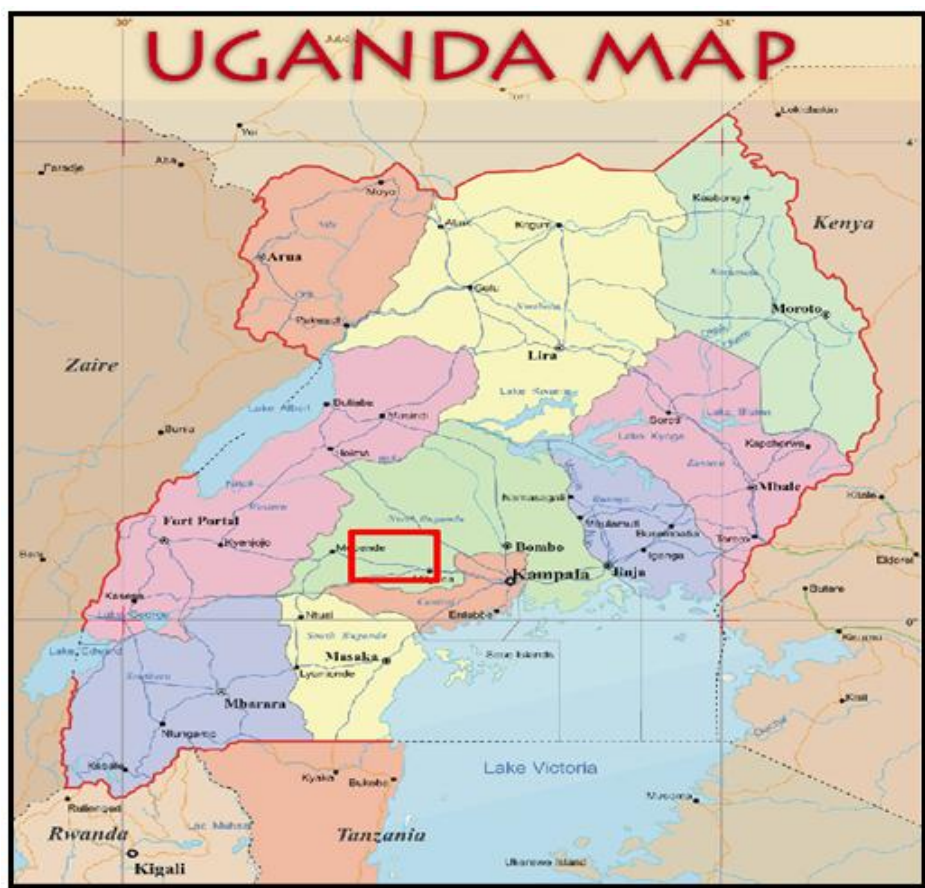

Figure 1: Map of Uganda showing study area in red box 


\section{International Advanced Research Journal in Science, Engineering and Technology} ISO 3297:2007 Certified

Vol. 3, Issue 10, October 2016

It is about 120 kilometers from Kampala town accessible by road. It boarders the districts of Mityana and Mubende to the South, Hoima to the north, Kibaale to the west and Nakaseke to the east. The location is between latitudes $0^{0} 55^{\prime} 54.06 " \mathrm{~N}$ and $0^{0} 47^{\prime} 7.62 " \mathrm{~N}$ and longitude $31^{\circ} 28^{\prime} 15.58^{\prime \prime} \mathrm{E}$ and $32^{\circ} 14^{\prime} 29.57^{\prime \prime} \mathrm{E}$.

Singo granite falls within the Buganda - Toro system that intrudes metasedimentary rocks that has experienced both contact and low-grade metamorphism. The Singo and Mubende granite batholiths were emplaced after the granitic gneisses which are the oldest in the area are formed part of the basement complex (Figure 2) [5]. The granite is cut with aplite dykes, quartz veins, hematite veins, breccias and shear zones, steep joints and sinistral faults. The granite is massive, coarse grained and greyish in colour along the contact, although pink and red shades are frequent in the central part of the rock [6]. Dykes and irregular bodies of sericitised granite are widely spread. In some places, foliation is present as defined by parallel alignment of long axes of some of the feldspar phenocrysts. There is zonation in texture, mineralogy and geochemistry from the center and comprises mainly of plagioclase, quartz, biotite, muscovite and opaque [7]. The granite is associated with some minerals like alluvial gold, fluorite, wolframite etc, which are economically mined in the past [6].

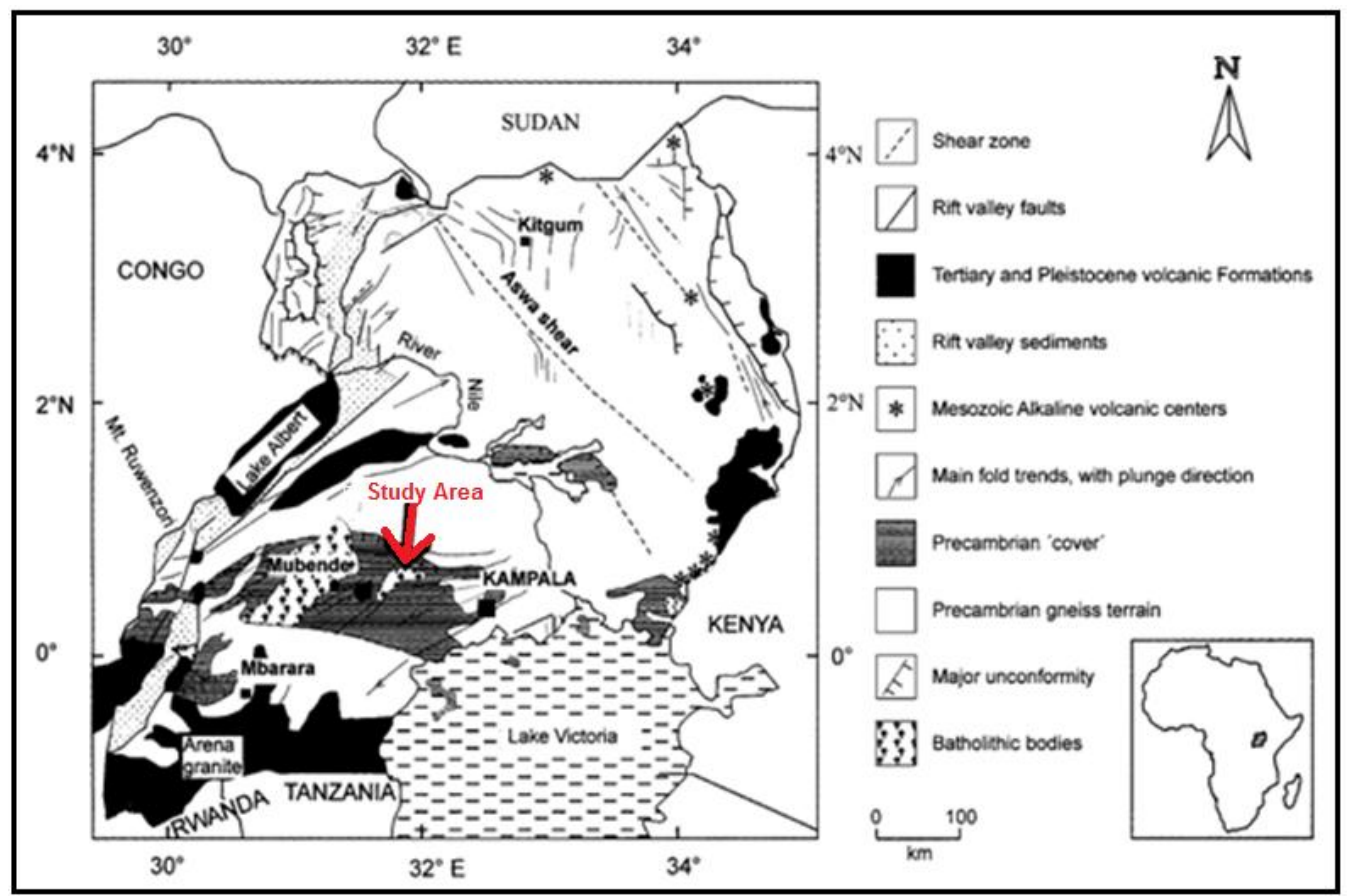

Figure 2: Simplified geological map of Uganda showing the location of Singo granite modified after (Nagudi et. al., 2003)

\section{METHODOLOGY}

The airborne magnetic data was processed and analysed using OASIS Montaj from Geosoft, and ESRI Arcmap 10.0 was employed for visualizations and map generation. Various methods of filtering were employed to enhance data interpretation, these include; Vertical Derivatives, Analytical Signal, and Total Magnetic Intensity. Vertical derivative narrows the width of anomalies and therefore locates the source bodies. It also enhances shallow sources, while suppressing deeper ones and gives a better resolution of closely spaced sources. Analytical signal locates the edges of magnetic source bodies and defines source positions regardless of any remanence in the sources [8]. Total magnetic intensity identifies the amplitude of the magnetic anomaly and indicates other subsurface structures. The depths and locations of the magnetic anomaly sources were observed using 3D Euler deconvolution process.
This method provides information about depth and gives an indication of the causative bodies from the airborne magnetic field [9], it uses gradients, either measured or calculated. To calculate the $3 \mathrm{D}$ Euler deconvolution the data does not need to be pole-reduced [10] and the technique can outline confined sources, vertical pipes, dikes and contacts. The theory behind the 3D Euler deconvolution can be found in literature [10-11].

\section{RESULTS AND DISCUSSION}

\subsection{Vertical Derivatives}

The vertical derivative map (Figure 3) shows the outline of the Singo granite as the major feature, it also shows the prominent dykes oriented in the NW and SE direction while the NE-SW direction were less pronounce. The NW - SE structures particularly on southwestern side of the 


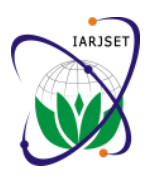

\section{International Advanced Research Journal in Science, Engineering and Technology}

ISO 3297:2007 Certified

Vol. 3, Issue 10, October 2016

study area were so pronounced, such that the identification In addition, the central part of the study area has sub of the circular part of the Singo granite almost become circular features, which is somehow related to the shearing indistinctly defined (double arrow area). effect (shown by single arrow).

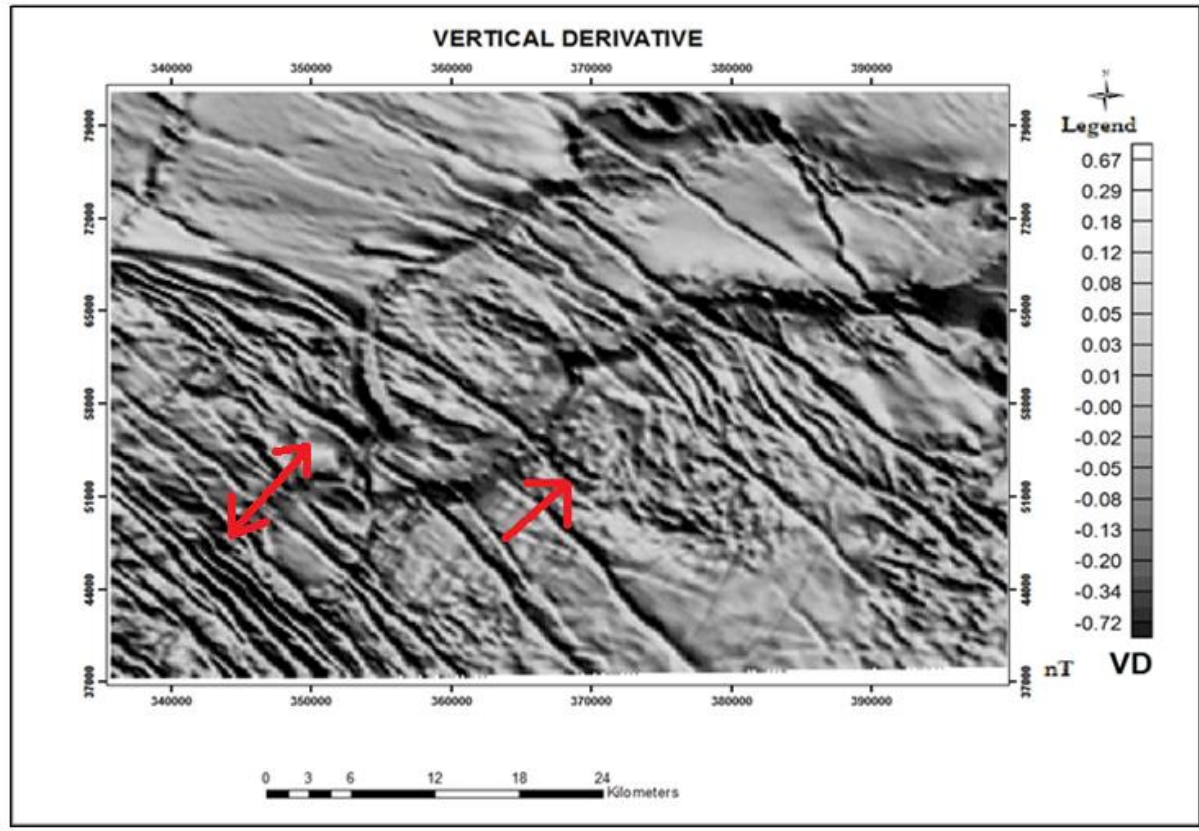

Figure 3: Resulting map of Vertical Derivatives

\subsection{TOTAL MAGNETIC INTENSITY}

has amplitudes of $-585 \mathrm{nT}$, this anomaly forms broad The resulting map of total magnetic intensity (Figure 4) features but of variable width that seems to be associated shows a relatively low and moderate magnetic field with with Singo granite, though their relationship is not laterally extensive magnetic anomalies to the NW and SE distinctively defined. Other characteristic features of the study area. The amplitudes of the moderate observed include dyke intrusion. Some of the dykes that magnetic field range from -103 to $-142 \mathrm{nT}$. Linear traces cut the high magnetic anomalies show low magnetic of high frequency magnetic sources follow the entire outer intensity, which might be due to thin weathered zone margin of Singo granite with amplitude above 90nT. around them.

Another high frequency but negative magnetic anomaly

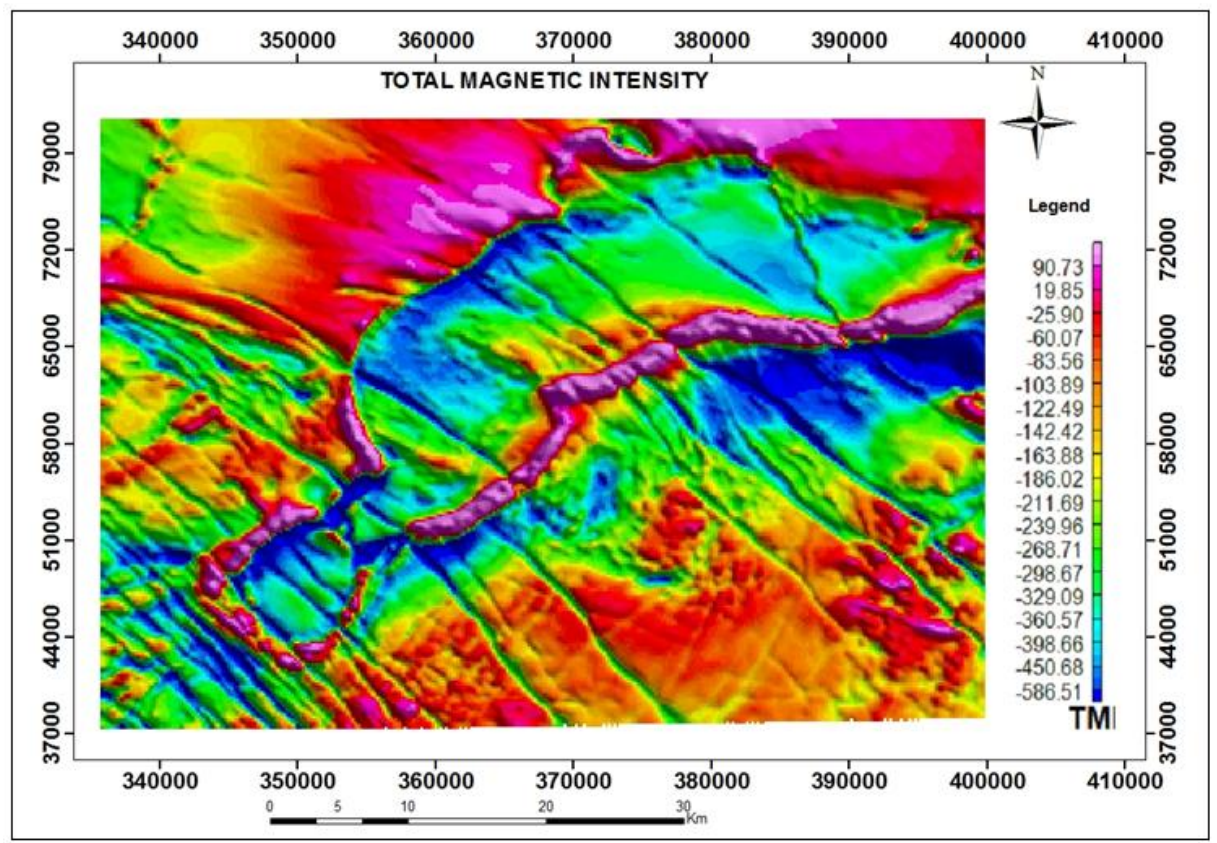

Figure 4: Resulting map of Total Magnetic Intensity 


\section{International Advanced Research Journal in Science, Engineering and Technology}

ISO 3297:2007 Certified

Vol. 3, Issue 10, October 2016

\subsection{Analytical signal}

The analytical signal filtered out the near surface source, possibly related to weathering of metasediments. The high frequency sources around Singo granite (Figure 5) are clearly defined by continuous sources that break in part to form isolated sources, which indicate that the sources could be linked to xenoliths with tourmalised margin. The dyke intrusions are clearly defined by high frequency sources as against low magnetic susceptibility interpreted with total magnetic intensity (Figure 4); this confirms that they are covered by weathered materials.

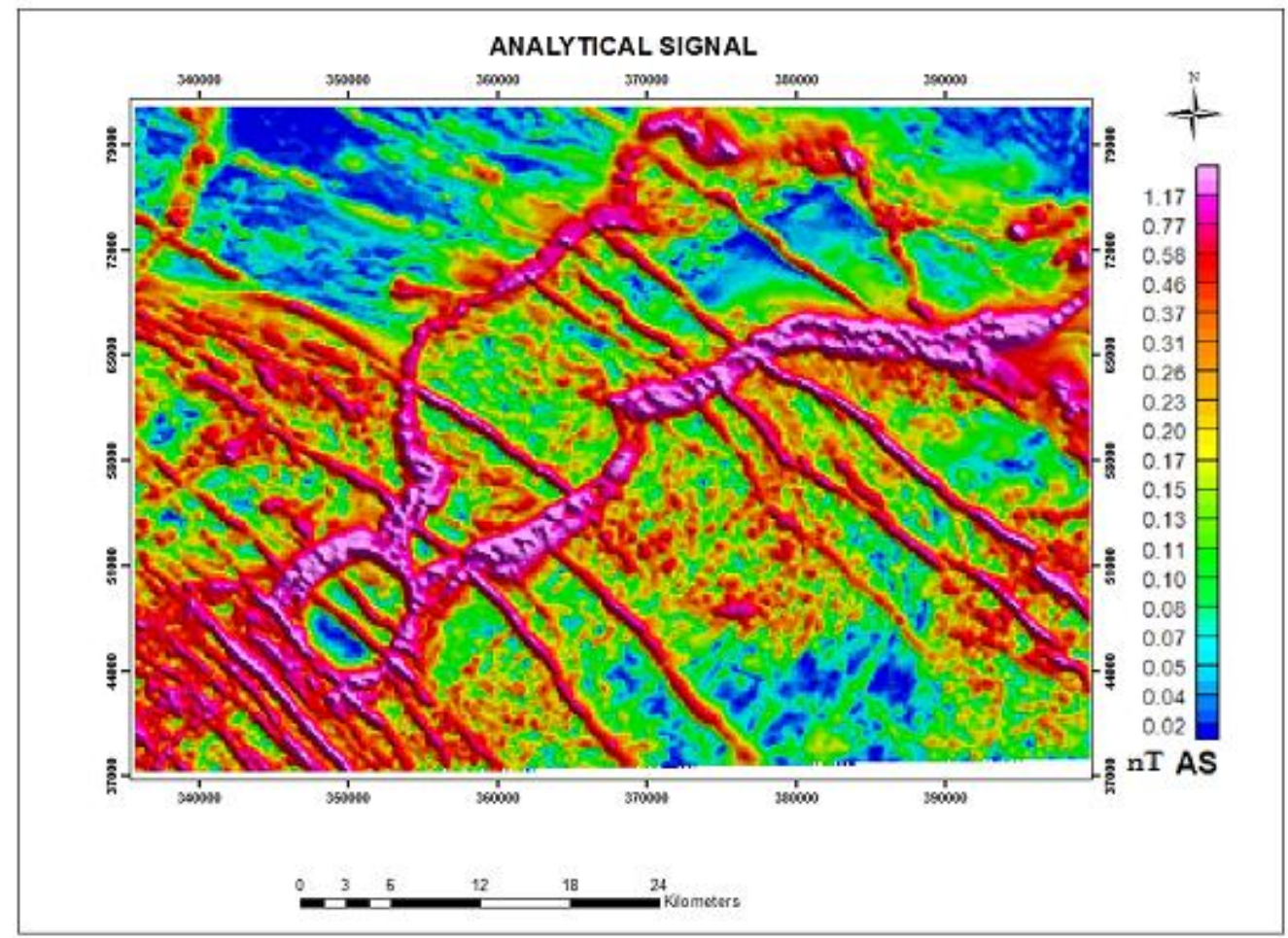

Figure 5: Resulting map of Analytical Signal

4.4 3D Euler Deconvolution

The result from 3D Euler Deconvolution shows two distinct features over the study area; these include linear features and isolated aggregate with deep sources (Figure $6)$. The linear features can be grouped further into NW-SE and the NE-SW structures. The NW-SE structures are the most widespread in the area. The magnetic source of the NW-SE structures is largely confined to a zone of 300400m (shown as deep blue colour).

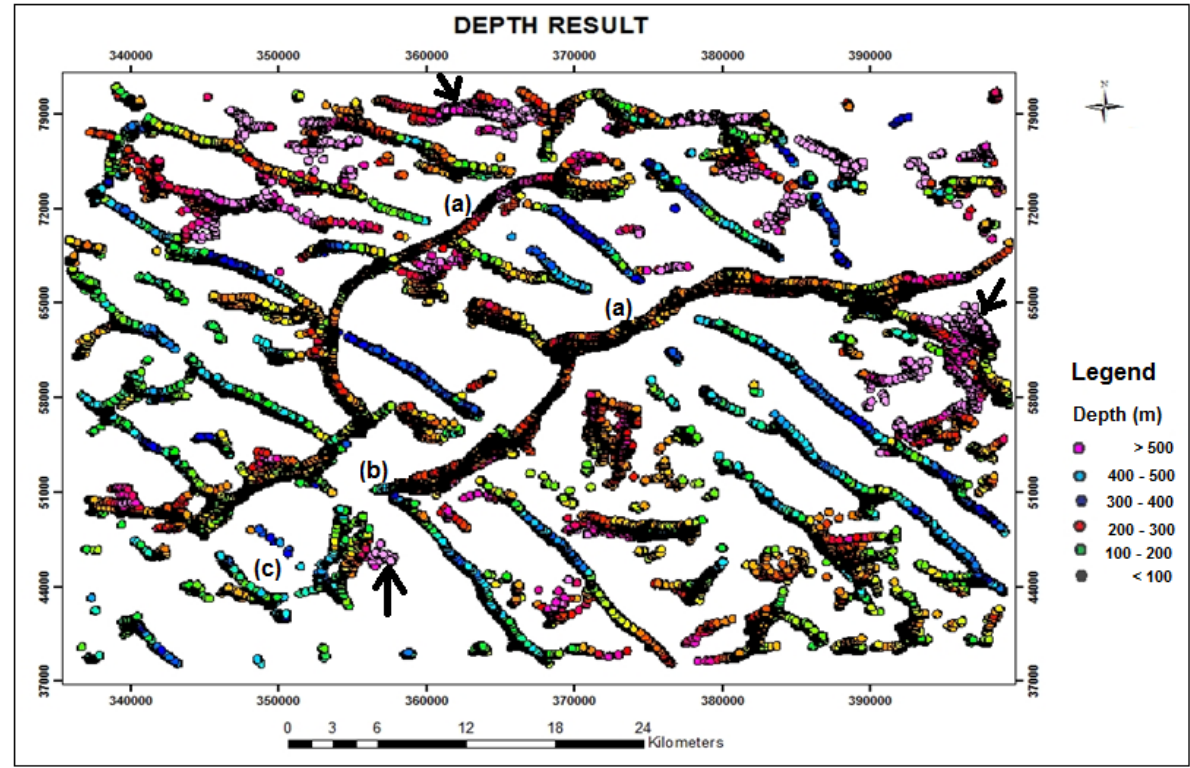

Figure 5: Resulting map of 3D Euler Deconvolution 
However, few of these sources occur at shallow depth of $100-200 \mathrm{~m}$. Towards the northwestern part of the map, a unique range of depth 200-300m occurs, although not widespread. The Singo granite occur as two main subparallel lineaments (indicated as (a)) trending NE-SW. In the southwestern part, it become circular (b area), which later breaks to form a complete circle at its termination point (c area). The magnetic sources along this NE-SW are mostly shallow having depth between $100-200 \mathrm{~m}$ with the circular feature on the southwestern side having source of 200-300m.

The isolated deep sources occurred mainly on the northern part of the study area running in a poorly defined E-W trend. Another significant cluster is found on the eastern part of the study area. On the western part, only significant and much localized sources are found there. The main characteristic of these sources is that they attain depth greater than $500 \mathrm{~m}$ (they are indicated by black arrow).

\section{CONCLUSION}

The study shows the significant of remote sensing data (aeromagnetic data) in mapping geological features. The analytical signal map sharpened the boundary between the Singo granite and the metasediments, as well as enhancing the structural features (NE-SW, NW-SE, E-W), indicating that these structures which show low magnetic susceptibility were covered by weathering as analytical signal process filtered them out. The vertical derivative was useful in identifying the sub-circular structures in the central part of the study area, which is related to shearing effect. 3D Euler deconvolution was used to determine the depth of the magnetic sources associated with the anomalies. The linearized sources are oriented in either NW-SE or NE-SW, with NW-SE being widely distributed. Most of these magnetic sources are confined in the zone between $300-400 \mathrm{~m}$ but some are localized within shallow depths (100-200m). The identification of the shear zones and areas of localized tectonic activity in the southwestern part of the study area provides significant information in targeting mineralization zones [12].

\section{REFERENCES}

[1] Blakely, R.J., Wells, R.E., Weaver, C.S., and Johnson, S.Y., 2002, Location, structure, and seismicity of the Seattle fault zone, Washington: Evidence from aeromagnetic anomalies, geologic mapping, and seismic-reflection data: Geological Society of America Bulletin, v. 114, p. 169-177.

[2] Grauch, V., 2001, High-resolution aeromagnetic data, a new tool for mapping intrabasinal faults: Example from the Albuquerque basin, New Mexico: Geology, v. 29, p. 367-370.

[3] Lunden, B., Wang, G., and Wester, K., 2001, A GIS based analysis of data from Landsat TM, airborne geophysical measurements, and digital maps for geological remote sensing in the Stockholm region, Sweden: International Journal of Remote Sensing, v. 22, p. 517532.

[4] Taylor, P.T., Zietz, I., and Dennis, L.S., 1968, Geologic implications of aeromagnetic data for the eastern continental margin of the United States: Geophysics, v. 33, p. 755-780.

[5] Nagudi, B., Koeberl, C., and Kurat, G., 2003, Petrography and geochemistry of the Singo granite, Uganda, and implications for its origin: Journal of African earth sciences, v. 36, p. 73-87.
[6] Johnson, R.J., and Williams, C., 1961, Explanation of the geology of sheet 59 (Kiboga), Government Printer.

[7] Nyakairu, G.W., and Koeberl, C., 2001, Mineralogical and chemical composition and distribution of rare earth elements in clay-rich sediments from central Uganda: Geochemical Journal, v. 35, p. 13-28.

[8] Verduzco, B., Fairhead, J.D., Green, C.M., and MacKenzie, C., 2004, New insights into magnetic derivatives for structural mapping: The Leading Edge, v. 23, p. 116-119.

[9] Geosoft, 2010, Online Manuals, Tutorials and technical notes; Gravity \& Magnetic Interpretation (Euler 3D).

[10] Reid, A., Allsop, J., Granser, H., Millett, A., and Somerton, I., 1990, Magnetic interpretation in three dimensions using Euler deconvolution: Geophysics, v. 55, p. 80-91.

[11] Thompson, D., 1982, EULDPH: A new technique for making computer-assisted depth estimates from magnetic data: Geophysics, v. 47, p. 31-37.

[12] Borg, G., Lyatuu, D., and Rammlmair, D., 1990, Genetic aspects of the Geita and Jubilee Reef Archean BIF-hosted gold deposits, Tanzania: Geologische Rundschau, v. 79, p. 355-371. 